\title{
Morphological, histological and radiological study of calcified placenta and its relation with fetal outcome
}

\author{
Pushpa Goswami ${ }^{1}$, Samreen Memon, ${ }^{2}$ Dr. Kusum Pardeep ${ }^{3}$ \\ ${ }^{I}$ Assistant Professor of Anatomy Liaquat University of Medical and Health Sciences Jamshoro, Sindh Pakistan \\ ${ }^{2}$ Assistant Professor and Head of Anatomy department Liaquat University of Medical and Health Sciences \\ Jamshoro, Pakistan \\ ${ }^{3}$ Associate Professor of Radiology Liaquat University of Medical and Health Sciences Jamshoro, Sindh \\ Pakistan
}

\begin{abstract}
The placenta is a distinctive organ, which facilitates the supply of oxygen and nutrients to the fetus through placental microcirculation. Placenta potentially plays a key role in the etiology of developmental programming through its impact on nutrient transfer. Placental transport efficiency depends on a variety of parameters, including surface area for exchange, thickness of the placental membrane. The aim of this study is to see the morphological, histological and radiological changes in excessive placental calcification and its relation with fetal outcome. This retrospective study was conducted at the department of Anatomy of Liaquat University of Medical \& Health Sciences Jamshoro. One hundred twenty placentae were collected from labor room and gynecology operation theatre of Liaquat University Hospital. Forty placentae from parturient that PIH, forty from parturient having placental abruption \& forty placentae from parturient belonged to normal pregnancy (Control Group). Age of all parturient is between 17 to 32 years. The study of gross morphology of placenta was done in the department of anatomy. Approximately five mm piece of placenta was taken and processed for histological study. Radiological study was done in the department of radiology of LUH Jamshoro. Highly significant $(p=<0.001)$ difference seen in placental abruption and PIH group than normal.
\end{abstract}

Key words: calcification, Placenta, PIH, placental abruption, radiology

\section{Introduction}

Placenta is the most important endocrine organ with intimate relation to fetus. It is the functional center of the maternal-fetal system and is responsible for respiratory, nutritional, excretory, endocrine, and immunological functions. Placenta is actually a window providing insight vision for understanding maternal dysfunction and its impacts on fetal well being. Although it has long has been underappreciated and understudied by the scientific society. Inappropriate function of this critical organ causes many fetal abnormalities. [1, 2, 3]

Calcification is common in human placentae and known as a normal feature of maturation and senescence of this organ. Increased calcification of placenta has serious negative consequences like fetal growth restriction and fetal distress is seen in excessively calcified placenta four times more than in the uncalcified group. [4]

Deposition of calcium salts is heaviest on the maternal surface in the basal plate, along the septa, basement membrane of placental villi, perivillous space and sub chorionic space, degenerative villi also show calcification. Morphologically calcium deposits are seen as white or pale color fine granules or clumps often felt as gritty deposits. Histological calcification appears intracellular as well as extra cellular basophilic deposits on haematoxylin and eosin staining. [5, 6, 7]

This episodic calcification is normally associated with tissue aging due to the induction of some age related dystrophic changes in the placenta. But there are certain conditions seen in mother which leads to excessive placental calcification such as Pregnancy induced hypertension $(\mathrm{PIH})$, Placental abruption, intra uterine growth restriction (IUGR), cigarette smoking. These complications of pregnancy are reflected in structure and function of the placenta. Out of these various conditions, placental calcification in PIH and placental abruption was observed in this study on the basis of morphology, histology and radiology and also its relation with fetal outcome was observed [8]

In normal pregnancies, placental separation occurs soon after birth, while in pregnancies complicated by abruption, the placenta begins to detach before birth and causes bleeding from the genital tract known as ante partum hemorrhage (APH). Pregnancy-induced hypertension (PIH) is defined as hypertension during pregnancy when associated with new-onset proteinuria. Both conditions are major cause of perinatal mortality and maternal morbidity in the developing countries like Pakistan. The etiology of both conditions remains unknown. It is supposed to be that abnormal trophoblast invasion leading to rupture of the spiral arteries and premature 
separation of the placenta followed by death of placental tissue and so forth accumulation of calcium in case of abruption and in PIH abnormal trophoblast invasion of maternal spiral arteries which fails to dilates and results in decreased uteroplacental perfusion causing placental dysfunction resulting in fetal growth restriction, reduced fetal length, and preterm delivery. $[9,10,11]$

An adequate knowledge of the morphometry of the placenta and its clinical relevance can prove to be valuable in the early assessment of the fetal well being.

\section{Material And Methods}

This case control study was conducted at the department of Anatomy of Liaquat University of Medical \& Health Sciences Jamshoro Sindh Pakistan to assess the morphological changes in excessive placental calcification and its relation to the fetal outcome. Hundred and twenty placentae were collected from labor room and gynecology operation theatre of Liaquat University Hospital. Forty placentae from parturient that had pregnancy induced hypertension \& forty placentae from parturient with history of Abruption of placenta \& forty cases belonged to normal pregnancy (Control Group). Age of all mothers was between 17 to 32 years.

\subsection{Study of placental calcification on Morphology}

Placentas was washed in running tap water, tagged with code numbers and were preserved in $10 \%$ formalin solution for 48 hours for fixation. The study of gross morphology was done in department of Anatomy of LUMHS placentae were measured on a weighing machine graduated in grams diameter was measured with the help of a measuring tape in centimeters and visible calcification is also noted.

\subsection{Study of placental calcification on Histology}

Placenta was cut along the maximum diameter into two halves. Approximately one $\mathrm{cm}$ piece of placenta was cut from one half and were processed for routine paraffin embedment, sections were made of 5 $\mathrm{mm}$ ribbons with the help of automatic microtome and slides were prepared, stained with $\mathrm{H} \& \mathrm{E}$ and von kossa special stain for calcium. Areas of placental calcifications were counted with the help of microscope and photo micrographs were taken as described previously $[12,13]$.

\subsection{Study of placenta on radiography:}

Radiographic study of calcified placenta was performed on Allangior 500 MA machine with Fuji films in the Department of Radiology LUH. The placentae lay out with flat maternal surface downward in plastic tray which was placed on the x-ray plate. The exposure factors were as follows: 0.2 seconds; $50 \mathrm{~mm}$ fine focus using $50 \mathrm{kV}$ and a tube film distance of 40 inches. Radiographs were labeled according to corresponding code numbers. Assessment of placental calcification on radiology was performed by expert Radiologist.

The placentae were graded according to the number of foci of calcification as shown under:

Grade 0 ............ No calcification.

Grade 1............Slight (two foci of calcification present)/field

Grade 2................ Moderate (3-6 foci of calcification present)/ field

Grade $3 \ldots \ldots \ldots \ldots . . .$. Severe (more than 6 foci of calcification present or diffuse)/field [14]

\section{Results}

The study of gross morphology of all placentae was conducted in the Department of Anatomy at Liaquat University of Medical \& health sciences Jamshoro. Calcification was assessed and verified on light microscopy and radiology. All the features and calcification visible on gross, histology and on radiology were recorded on the proforma. The results of the study are depicted in text and tables.

Table-1 shows placental parameter and fetal weight with statistical analysis of placental parameters show highly significant $(\mathrm{p}=<0.001)$ difference in weight and diameter of placenta in abruption of placentae and PIH group as compared with control group. The weight of the new born in abruption of placentae and PIH group differs from control group significantly $(\mathrm{p}=0.001)$. There was a tendency of low birth weight in abruption of placentae and PIH groups than control group. The lower birth weight of new born was surprisingly observed in abruption of placentae as compared to PIH.

Table-2 shows fetal outcome in abruption of placentae and PIH which is poor than control. Four major outcomes including still birth, intrauterine death, alive with Apgar score 03 or more than 05 were analyzed.

Table-3 and Table 4 shows number of calcified areas per low power field (X10) on microscopy and grading of placental calcification on radiology. Areas of calcification in Abruptio placentae and PIH differ from control group significantly $(\mathrm{p}=<0.001)$. 
Table 1: Shows placental weight and diameter and weight of new born

\begin{tabular}{|l|l|l|l|l|l|l|}
\hline Placental weight in gms. & Min. wt & Max. wt & Mean & SEM & Std & P value \\
\hline In control & 450 & 650 & 526.25 & 8.414 & 53.214 & \\
\hline In PIH & 200 & 550 & 432.25 & 11.889 & 75.192 & $<.0001$ \\
\hline In Abruptio placentae & 180 & 400 & 284.88 & 9.084 & 57.451 & $<.0001$ \\
\hline Placental diameter in cms & Min. & Max. wt & Mean & SEM & Std & P value \\
\hline In control & 19 & 24 & 21.225 & 2148 & 1.3585 & \\
\hline In PIH & 10 & 16 & 14.208 & 1914 & 1.2103 & $<.0001$ \\
\hline In Abruptio placentae & 10.0 & 16.5 & 13.070 & 0.2504 & 1.5838 & $<.0001$ \\
\hline Weight of newborn in kg. & Min. Wt & Max. wt & Mean & SEM & Std & P value \\
\hline In control & 1.8 & 3.6 & 2.790 & .0689 & .4361 & .449 \\
\hline In PIH & 1.4 & 3.0 & 2.195 & .0703 & .449 & $<.0001$ \\
\hline In APH & 1.0 & 2.8 & 1.898 & .0660 & .4172 & $<.0001$ \\
\hline
\end{tabular}

Table 2: Shows fetal outcome

\begin{tabular}{|l|l|l|l|}
\hline Fetal outcome & Control & Abruptio placentae & PIH \\
\hline Still birth & $02(5 \%)$ & $06(15 \%)$ & $05(12.5 \%)$ \\
\hline Intra uterine death & $01(2.5 \%)$ & $12(30 \%)$ & $05(12.5 \%)$ \\
\hline Apgar score of 03 or less at 05 min & $05(12.5 \%)$ & $12(30 \%)$ & $10(25 \%)$ \\
\hline live with Apgar more than 05 & $32(80 \%)$ & $10(25 \%)$ & $20(50 \%)$ \\
\hline
\end{tabular}

Table 3: Shows number of calcified areas per low power field (x10) on microscopy with its statics.

\begin{tabular}{|l|l|l|l|l|l|l|}
\hline & $\begin{array}{l}\text { Minimum areas of } \\
\text { calcification }\end{array}$ & $\begin{array}{l}\text { Maximum } \\
\text { Areas of } \\
\text { calcification }\end{array}$ & Mean & $\begin{array}{l}\text { Std. } \\
\text { Error mean }\end{array}$ & $\begin{array}{l}\text { std. } \\
\text { Deviation }\end{array}$ & P value \\
\hline Control & 1 & 5 & 2.93 & .210 & 1.328 & \\
\hline $\begin{array}{l}\text { Abruptio } \\
\text { placentae }\end{array}$ & 6 & 22 & 13.00 & .768 & 4.857 & $<.0001$ \\
\hline PIH & 10 & 20 & 14.97 & .445 & 2.815 & $<.0001$ \\
\hline
\end{tabular}

Table 4: Shows radiological grading of placental calcification

\begin{tabular}{|c|c|c|c|}
\hline Grades of calcification & Control & Abruptio placentae & PIH \\
\hline 0 & 25 & 00 & 00 \\
\hline 1 & 13 & 00 & 10 \\
\hline 2 & 02 & 15 & 30 \\
\hline 3 & 00 & 25 & 2.62 \\
\hline Mean & 0.42 & 2.75 & 0.78 \\
\hline SEM & 0.094 & 0.069 & $<.0001$ \\
\hline p value & & $<.0001$ & \\
\hline
\end{tabular}
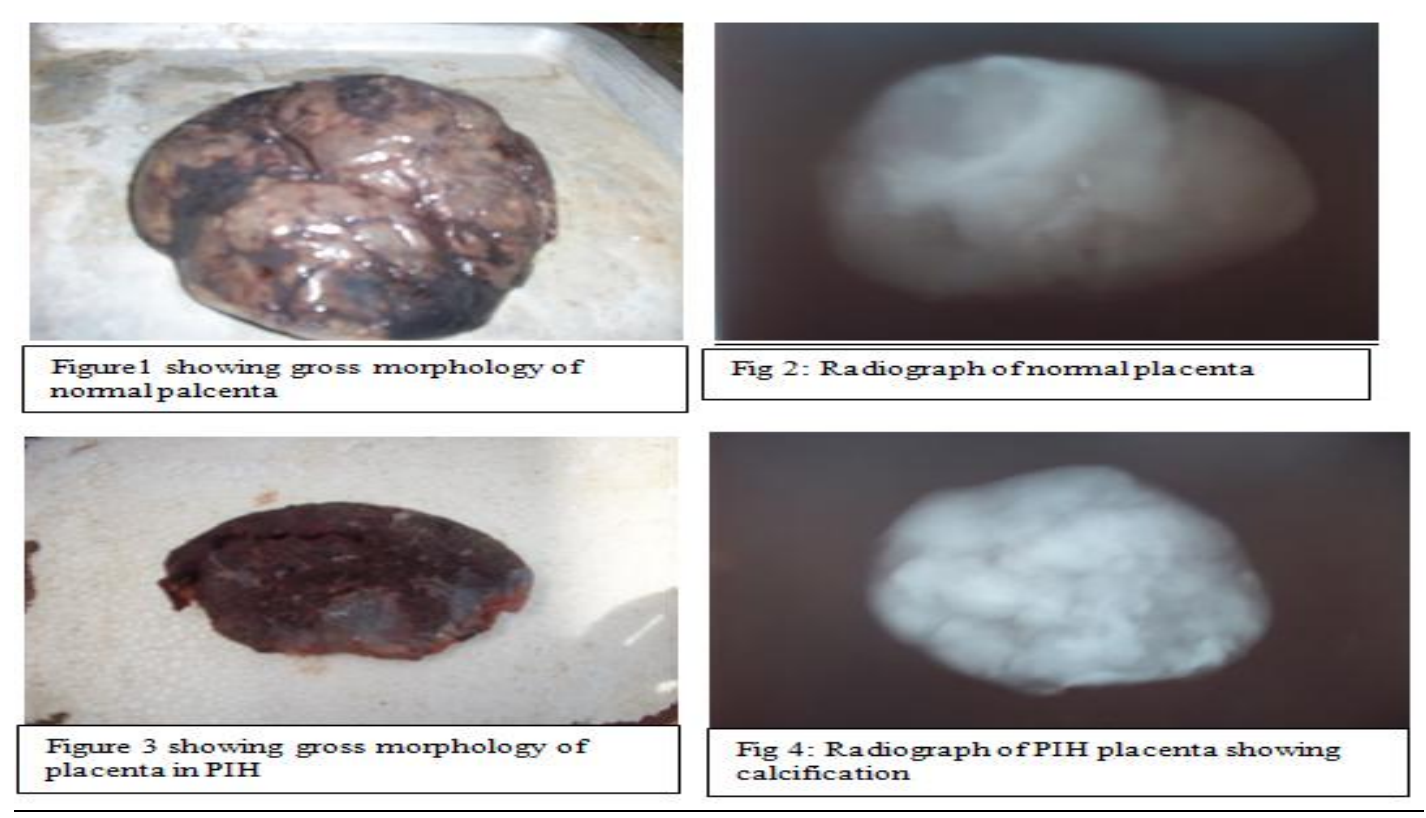


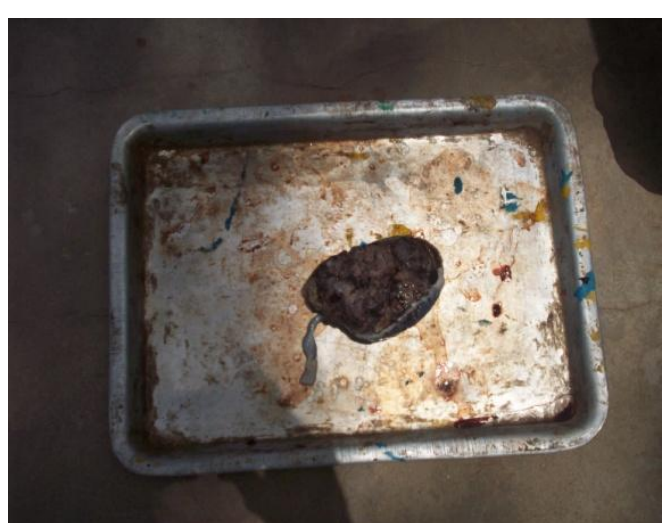

Figure 5 showing gross morphology of placenta in abruption

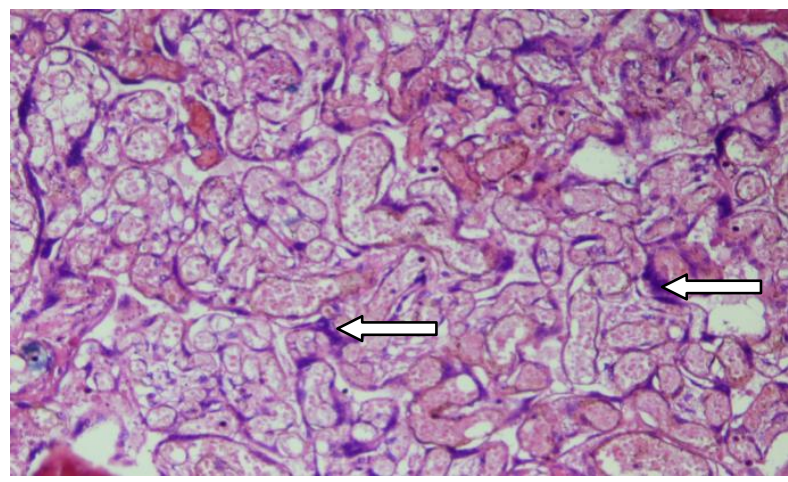

Figure 7 showing calcification in normal placenta by arrow on H\&E staining

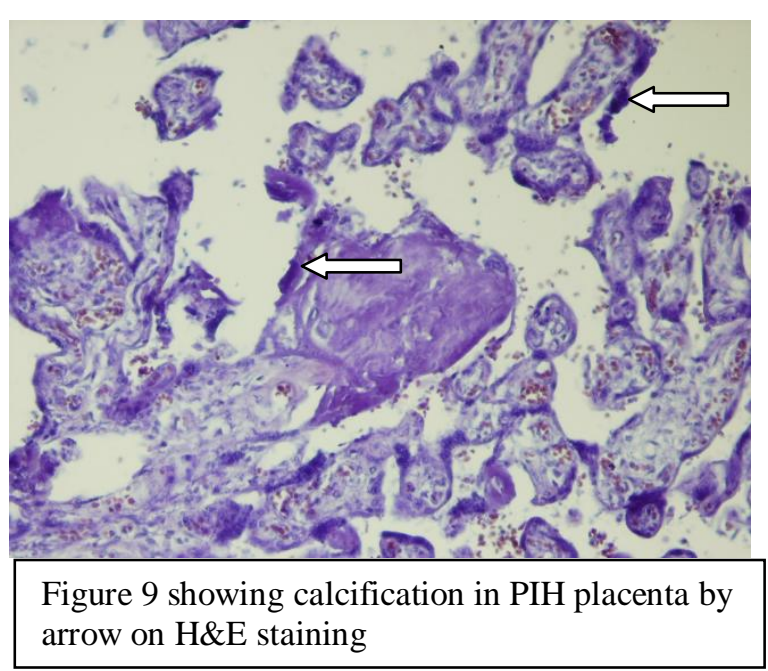

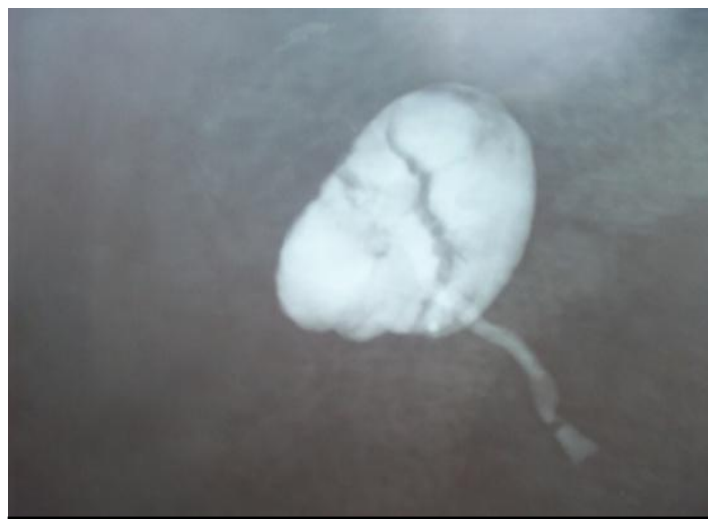

Fig 6 Radiograph of abruption placenta showing calcification

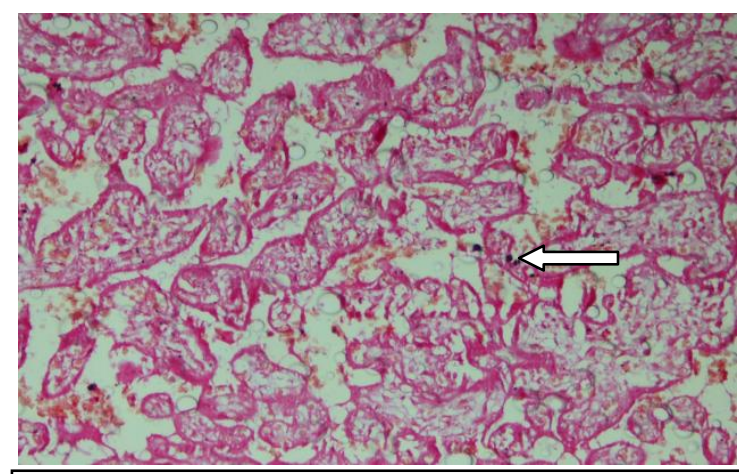

Figure 8 showing calcification in normal placenta by arrow on von kossa staining

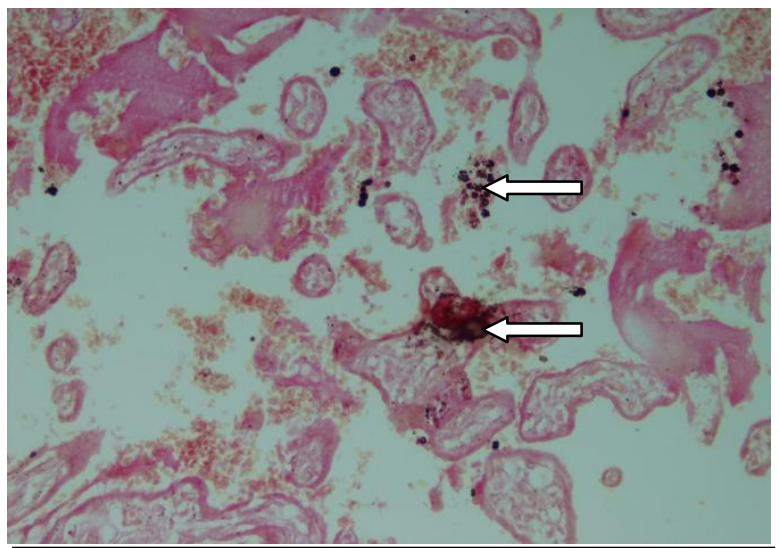

Figure 10 showing calcification in PIH placenta by arrow on von kossa staining 


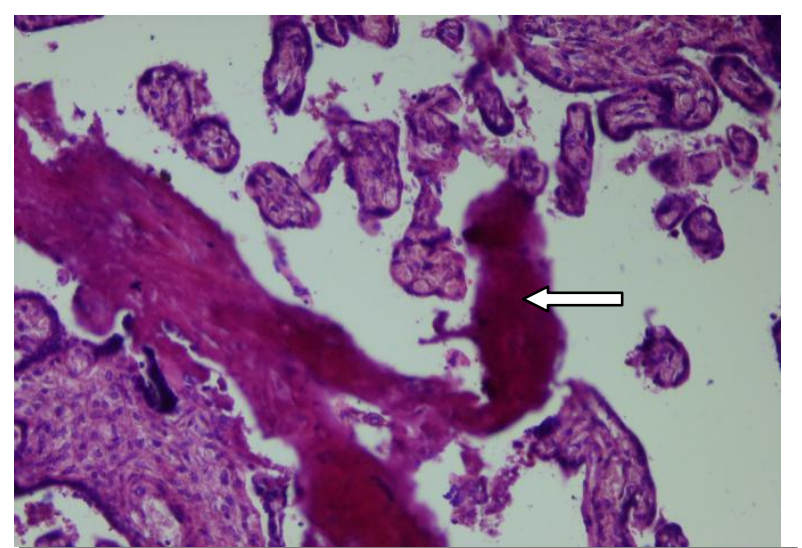

Figure 11 showing calcification in abruptio placenta by arrow on H\&E staining

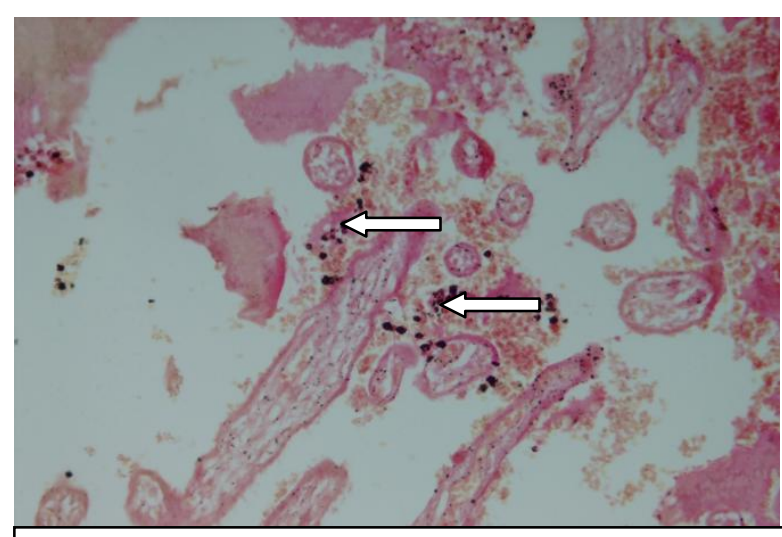

Figure 12 showing calcification in abruptio placenta by arrow on von kossa staining

\section{Discussion}

The placenta is characteristic feature of eutherian or "placental" mammals which connects the developing fetus to the uterine wall to allow nutrient uptake, waste elimination, and gas exchange via the mother's blood supply. Calcification is common in human placentae and recognized as normal part of maturation and aging of this organ. The pathological maturation of placenta because of excess calcification can lead to fetal growth restriction which is the second most common cause of perinatal death. Early preterm placental calcification is associated with a higher incidence of poor pregnancy outcome, both in mother (postpartum hemorrhage, maternal transfer to the intensive care unit) and fetus (including preterm birth low birth weight, low Apgar score and neonatal death). [15]

This retrospective study was based on morphological, histological and radiological examination of 120 placentae for excessive placental calcification and its effect on fetal outcome. Out of 120 placentae, 40 placentae belonging to patient of Abruption placentae and 40 of patient with PIH and 40 of normal parturient.

The weight of placenta in control group ranges from 450 to $650 \mathrm{gm}$ with a mean weight of 526.25 $8.414 \mathrm{gm}$ (mean \pm SEM). In PIH group weight of placenta ranges from 200 to $550 \mathrm{gm}$ with a mean weight of $432.25 \pm 11.889 \mathrm{gm}$ (mean $\pm \mathrm{SEM}$ ). In Abruption of placentae group the weight of placenta ranges from 180 to $400 \mathrm{gm}$ with a mean weight of $284.88 \pm 9.084 \mathrm{gm}$ (mean $\pm \mathrm{SEM}$ ). Our study shows reduced placental weight $(66 \%)$ in patient of abruption placentae and PIH then placentae of parturient in control group, same has been cited by Sultana S, Hossain GA in 2006 and by Rahman MA, Rahman MH in 2007 in their study they found reduced placental weight in $(50 \%)$ of cases. Palaskar PA, Chaudhary KR, Mayadeo NM have shown reduced placental weight in $77 \%$. [16, 17, 18]

The diameter of placenta in control group ranges from 19 to $24 \mathrm{~cm}$ with a mean of $21.225 \pm 0.2148 \mathrm{~cm}$ (mean \pm SEM). In PIH group diameter of placenta ranges from 10 to $16 \mathrm{cms}$ with a mean $14.208 \pm 0.1914 \mathrm{~cm}$ $($ mean $\pm \mathrm{SEM})$. In Abruption of placentae group the diameter of placenta ranges from 10 to $14 \mathrm{~cm}$ with mean $13.070 \pm 0.2504 \mathrm{~cm}$ (mean $\pm \mathrm{SEM}$ ). In our study less placental diameter was seen in $66 \%$ of cases. Sultana $S$, Hossain GA, Rahman MH, Hasan N, Sultana SZ, Khalil M in 2007 have reported less placental diameter in (55\%) of cases in patient of PIH, which is nearly same as seen in our study. Whereas different results have been observed by Ashfaq M, Janjua M.Z, Channa M.A in 2005 showing no difference in weight and diameter in placentae with PIH and normal group. [19, 20]

In our study and study performed by Udaina A in 2001 and Sarwar I in 2006 uteroplacental insufficiency was found to be the leading cause of low birth weight of the new born. The weight of new born baby in control group ranges from $1.8 \mathrm{~kg}$ to $3.6 \mathrm{~kg}$ mean weight of $2.790 \pm 0.0689$ (mean $\pm \mathrm{SEM}$ ), in abruption of placentae group fetal weight ranges from $1.0 \mathrm{~kg}$ to $2.8 \mathrm{~kg}$ with a mean weight of $1.898 \pm 0.0660 \mathrm{of} \mathrm{kg}$ (mean \pm SEM).Similarly in PIH group the fetal weight ranges from $1.4 \mathrm{~kg}$ to $3.0 \mathrm{~kg}$ with a mean weight of 2.195 $\pm 0.0703 \mathrm{~kg}$ (mean \pm SEM). There was a tendency of low birth weight in abruption of placentae and PIH groups than that of control group. The study conducted by, Hairi NN, Rahman LA, Salleh N shows, that pregnancyinduced hypertension was found to be an independent risk factor for low birth weight. [1, 21, 22]

Perinatal Mortality Rate (PMR) in Pakistan is 50-60/1000 which is one of the highest in the world as stated by Mufti P, Setna F, Nazir K; they mention the leading cause of perinatal mortality is low birth weight. Placental abruption and PIH was associated with 3.4-fold increased in perinatal mortality as shown in study conducted by Xiong X, Buekens P, Pridjian G, Fraser WD in 2007. In another study conducted by Yousfani S, 
Mumtaz F et al shows APH in (27.67\%) \& PIH in (23.21\%) are the major causes of perinatal mortality in our country. [23, 24, 25]

Calcifications were mostly observed in the villi and basement membrane of the villi which is strongly suggestive of uteroplacental insufficiency because of narrow lumen. We see calcification from one millimeter to biggest one of about 5 millimeters. Placental calcification was seen significantly more frequently in primigravidas as cited by Russel J G B, Fielden P same results were observed in this study. Similar results are cited by Spirit B A, Cohen W N, Weinstein H M. [26, 27]

In PIH and in abruption of placentae APH mean number of calcified areas on gross as well as on microscopy seen were more than in normal placenta. In the study conducted by Majumandar S in Kolkkata and by Sarkar M in Mahattma Gandhi institute of medical science Sew gram India they have observed similar findings. $[4,28]$

The fetal mortality and morbidity associated with abruption of placentae is found to be responsible for $30 \%$ of stillbirths and hypertensive diseases which is responsible for $28 \%$ of stillbirths. [29]

The abruption of placentae and PIH are considered to be predominate causes of still birth in 21/40 (52.50\%) and 18/40 (45\%) cases as reported by Patil Y and D'costa GF and by Sharief M and Manther AA. The perinatal mortality was $52.0 \%$ in hypertensive women compared with $29.8 \%$ for normotensive women. In another study conducted by Bibi S, Ghaffar S, Pir MA and Yousfani S shows placental abruption is responsible for low birth weight in 70\%, low APGAR score in $28 \%$ and high still births in $54 \%$ cases. [30, 31, 32]

\section{Conclusion}

Placental calcification is a normal physiological process occurring in pregnancy but if this process is exaggerated it becomes pathological and causes remarkable changes both macroscopic and microscopic. Excessive placental calcification causes uteroplacental insufficiency and compromises foetal circulation and growth. The presence of preterm placental calcification is a predictor of poor uteroplacental flow and worse pregnancy outcome, need closer monitoring for maternal and fetal well being. The prevention and proper management of the conditions responsible for excessive placental calcification can give better fetal outcome.

\section{References}

[1]. Udainia, A, Jain M.L. Morphological study of Placenta in pregnancy induced hypertension with its clinical relevance. J Anat Soc India 2001; 50(01):01 -06.

[2]. Lúcio H. Oliveira LH, Xavie CC, Lana AM.J Pediatr (Rio J) 2002;78(5):397-402

[3]. Anca M. Pasca and Anna A. Penn The Placenta: The Lost Neuroendocrine Organ Neoreviews 2010;11; 664-77

[4]. Sarkar M, Ingole IV, Ghosh SsK, Bhakta A, Das RS, Tandale S, Tarnekar AM. Calcification in Placenta. J Anat soc India 2007; 56(1):01-06.

[5]. Avery CR, Aterman K. Calcification of the basement membrane of placental villi J Path 2005; 103(3):199-200.

[6]. Wentworth P. Macroscopic Placental Calcification and Its Clinical Significance. Bjog 2005; 72 (2): $215-222$.

[7]. Kumar V, Abbas AK, Fausto N. Robbins \& Cotran pathological basis of disease. 7th ed. Phildilphia: Elesevier ; 2004 pp 41-42.

[8]. Agababov RM, Abshina TN, Suzina NE, Vainshtein MB, Schartburd PM. Link between the early calcium deposition in placenta and nanobacterial like infection. J Biosic 2007; 32(6): 1163-68.

[9]. Elsasser DA, Ananth CV, Prasad V, Vintzileos AM. Diagnosis of Placental Abruption: Relationship between Clinical and Histopathological Findings Eur J Obstet Gynecol Reprod Biol. 2010 February; 148(2): 125.

[10]. Singh S, Gugapriya TS. Micro anatomical analysis of hypertensive placenta A retrospective case control study. National $\mathrm{j}$ of clinical anatomy $2013 ; 2$ (1) p 5-10

[11]. Rasmussen S, Irgens LM. Fetal growth and body proportion in Preeclampsia. Obstet Gynaecol 2003; 101(3):575-83.

[12]. Baloch AH, Memon SF, Ansari AK. Comparison of placentae from hypertension associated pregnancies and normal pregnancies. JLUMHS 2012; 11(01):03-06

[13]. Goswami P, Lata H, Memon S, Khaskhelli LB.Excessive Placental Calcification Observed in PIH Patients and its Relation to Fetal Outcome. JLUMHS 2012; 11: (3) p 144-148

[14]. Tindall VR, Scott JS. Placental calcification: A study of 3,025 singletons and multiple pregnancies .BJOG 1965; 72:356-373.

[15]. Chen KH, Chen LR, Lee YH. Exploring the relationship between preterm placental calcification and adverse maternal and fetal outcome. ultrasound Obstet Gynecol. $2011 ; 37(3): 328-34$

[16]. Sultana S, Hossain GA, Rahman H, Hasan N,Manan S,Zannat S. Gross morphometry of human placenta in eclampsia. Mymensingh Med J 2006; 15(1):10-14.

[17]. Rahman MA, Rahman MH, Habib MA, Selimuzzaman SM. Placental changes in eclampia and fetal outcome. Mymensingh Med J 2007; 16(2):191-96.

[18]. Palaskar PA, Chaudhary KR, Mayadeo NM. Foeto-placental weight relationship in normal pregnancy and pre-eclampsia-eclampsia a comparative study. Bombay Hospital Journal 2001; 43(3):361-3.

[19]. Sultana S, Hossain GA, Rahman MH, Hasan N, Sultana SZ, Khalil M. Changes of placental diameter thickness and cotyledon in eclampsia .Mymensingh Med J 2007; 16(2):127-31.

[20]. Ashfaq M, Janjua M.Z, Channa M.A Effect of gestational diabetes and maternal hypertension on gross morphology of placenta. JAMCA $2005 ; 17(1): 44-7$.

[21]. Sarwar I, Abbasi A, Islam A.Abruptio placentae and its complications at Ayub teaching hospital Abbottabad. JAMCA2006; 18(1).

[22]. Rahman LA, Hairi NN, Salleh N. 99 Association between Pregnancy Induced Hypertension and Low Birth Weight; A Population Based Case-Control Study. Asia-Pacific Journal of Public Health 2008; 20(2); 152-158

[23]. Mufti P, Setna F, Nazir K. Early neonatal mortality: Effects of interventions on survival of low birth babies weighing 1000-2000g. JPMA 2007; 56:174 
[24]. Xiong X, Buekens P, Pridjian G, Fraser WD. Pregnancy-induced hypertension and perinatal mortality. J Reprod Med 2007; 52(5):402-6.

[25]. Yousafani S, Bibi S, Mumtaz F, Memon A, Kushk IA, Saeed F. Perinatal Mortality and Related Obstetric Risk Factors at a Tertiary Care Hospital of Hyderabad. JLUMHS 2008; 204-7

[26]. Russel J G B, Fielden P. The antenatal diagnosis of placental calcification Bjog 2005 ; (9): 813 - 816.

[27]. Spirit B.A, Cohen .N, Weinstein H. The incidence of placental calcification in normal pregnancy. Radiology 1982; 142:707-711.

[28]. Majumdar S, Dasgupta H, Bhattacharya K, Bhattacharya A. A Study of Placenta in Normal and Hypertensive Pregnancies.J Anat Soc India 2005; 54 (2): 1-9

[29]. Hossain N, Khan N,Khan NH. Obstetric causes of stillbirth at low socioeconomic settings. JPMA 2009; 59:744-46

[30]. Patil Y, D'costa GF. Causes of mortality in still birth-An Autopsy study. Bombay hospital journal 2007: 49 (2).

[31]. Sharief M, Manther AA. Abruptio placentae: perinatal outcome in normotensive and hypertensive patients in Basra, Iraq. Eastern Mediterranean Health Journal 1998; 04(2):319-323.

[32]. Bibi S, Yousfani S, Ghaffar S, Pir MA, Yousfani S.Risk factor and clinical outcome of placental abruption:a retrospective analysis.JPMA 2009; 59:672-74 